CONF $421101-70$

\title{
RECEIVED BY
}

HII ra?

ANL/MSD/CP-76596

$\because r \cdots \%$

DE93 $006 \$ 18$

$-\cdots+1$

\section{Comparisons of Observed and Simulated Atomic Structures} of $\mathrm{Pd} / \mathrm{NiO}$ Heterophase Interfaces*

\author{
M.I. Buckett, J.P. Shaffer, and Karl L. Merkle \\ Materials Science Division \\ Argonne National Laboratory, Argonne, IL 60439-4838
}

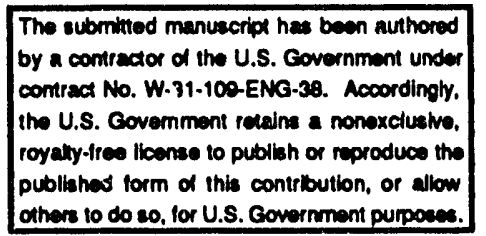

\section{DISCLAIMER}

\begin{abstract}
This report was prepared as an account of work sponsored by an agency of the United States Government. Neither the United States Government nor any agency thereof, nor any of their employees, makes any warranty, express or implied, or assumes any legal liability or responsibility for the accuracy, completeness, or usefulness of any information, apparatus, product, or process disclosed, or represents that its use would not infringe privately owned rights. Reference herein to any specific commercial product, process, or service by trade name, trademark, manufacturer, or otherwise does not necessarily constitute or imply its endorsement, recommendation, or favoring by the United States Government or any agency thereof. The views and opinions of authors expressed herein do not necessarily state or reflect those of the United States Government or any agency thereof.
\end{abstract}

*Work supported by the U.S. Department of Energy, Office of Basic Energy Sciences-Materials Sciences, under Contract No. W-31-109-Eng-38.

Manuscript submitted to the 1992 Fall Meeting of the Materials Research Society, Boston, Massachusetts, November 30-December 4, 1992 


\title{
COMPARISONS OF OBSERVED AND SIMULATED ATOMIC STRUCTURES OF Pd/NiO HETEROPHASE INTERFACES
}

\author{
M. I. BUCKETT, J. P. SHAFFER, AND KARL L. MERKLE
}

Materials Science Division, Argonne National Laboratory, Argonne, JL 60439

\section{ABSTRACT}

High-resolution electron microscopy (HREM) and image simulation using the multislice algorithm have been used to study the atomic structure of a $\mathrm{Pd} / \mathrm{NiO}(111)$ interface in an internally oxidized sample. Samples prepared in this way result in cube-on-cube oriented or twin-related precipitates whose (111) interfaces exhibit a contrast modulation along the boundary plane in the HREM image. Previous studies have reported that the observed structural period of this modulation corresponds qualitatively to the expected spacing if the boundary were composed of a network of misfit dislocations. In this study, rigid models of the (111) interface as viewed from the [110] direction were simulated using the EMS suite of programs. The questions we address are: (1) whether the terminating plane on the oxide side is made up of a $\mathrm{Ni}$ or an $\mathrm{O}$ layer, and (2) whether a rigid body translation normal to the interface exists. Finally, the results of the simulations are compared and contrasted to through-focal experimental images to investigate the origin of the contrast modulations and their possible relation to the extent of the misfit localization in these systems.

\section{INTRODUCTION}

Metal/ceramic interfaces are playing an increasingly important role in the development of high performance materials for new and existing technologies. Despite the wide range in interests, very little is presently known about the atomic structure and interactions which fundamentally control the interfacial properties of these systems. Recent high resolution electron microscopy (HREM) studies of simple fcc metal/metal-oxides have attempted to provide some insight into the question of atomic structure of heterophase interfaces [1-4]. These types of boundaries are readily prepared for HREM by internal oxidation of an alloy with very low (< a few atomic percent) solute concentration. When annealed in an appropriate partial pressure of oxygen, precipitation of the solute-oxide phase occurs such that the low energy interfaces make up the precipitate faces. A low index cube-on-cube or twin orientation relation generally develops between the precipitate and matrix, thus making HREM studies feasible. Metal/metal-oxide interfaces which have been prepared in this way and studied by $\mathrm{HREM}$ include $\mathrm{Pd} / \mathrm{NiO}$ [1], $\mathrm{Cu} / \mathrm{NiO}$ [1], $\mathrm{Ag} / \mathrm{CdO}$ [2], $\mathrm{Pd} / \mathrm{MgO}$ [3], $\mathrm{Cu} / \mathrm{MgO}$ [3], $\mathrm{Cu} / \mathrm{Al}_{2} \mathrm{O}_{3}$ [4] and $\mathrm{Nb} / \mathrm{Al}_{2} \mathrm{O}_{3}$ [5]. Other than in our own studies [6], HREM image simulations of $\mathrm{fcc}$ metal/metal-oxide systems have been performed only for $\mathrm{Ag} / \mathrm{CdO}$ and $\mathrm{Cu} / \mathrm{MgO}$. For the $\mathrm{Ag} / \mathrm{CdO}$ case, it was concluded that the (111) interface was incoherent. For the $\mathrm{Cu} / \mathrm{MgO}$ case, it was concluded that the (111) interface was partially coherent, being made up of a network of misfit dislocations. Both studies, however, provided only limited qualitative comparison of experimental to simulated images to support their conclusions.

The objective of the present study is to provide detailed comparisons of experimental to simulated HREM images of the (111) cube-on-cube interface in $\mathrm{Pd} / \mathrm{NiO}$ viewed along the [110] beam direction in order to evaluate the local atomic arrangements as well as the local defect structure, specifically the degree of coherence across the interface. The questions of whether the boundary plane on the oxide side is terminated with an oxygen or a nickel layer and whether a rigid body transiation exists normal to the boundary (volume expansion) are addressed. HREM simulations for a number of cases were performed: (1) rigid model with an oxygen plane as the terminating layer on the oxide side and no expansion normal to the interface; (2) rigid model with a nickel plane as the terminating layer on the oxide side and no expansion normal to the interface; (3) rigid models with an oxygen termination layer on the oxide side and with $0 \%, 5 \%$, and $10 \%$ expansions of the (111) plane spacing at the interface. For comparison, simulations of rigid models (oxygen terminated, no relaxations) of the higher misfit $\mathrm{Cu} / \mathrm{NiO}$ and $\mathrm{Cu} / \mathrm{MgO}$ (111) interfaces were also performed. 
A $\mathrm{PdNi}_{0.03}$ alloy was heat treated in air at $1273 \mathrm{~K}$ for $3 \mathrm{hr}$ to produce $\mathrm{NiO}$ precipitates sufficiently large for HREM investigation. Additionally, the samples were equilibrated in an Ar $0.02 \% \mathrm{O}_{2}$ atmosphere for $17-24 \mathrm{hr}$ and slow cooled to room temperature to minimize the residual strains. HREM was performed on a J4000 microscope operating at $400 \mathrm{keV}$.

HREM image simulations were performed using the multislice routines in the EMS suite of programs [7]. A diagram illustrating the periodic supercell used for the simulations is shown in Fig. 1(a),with the dimensions of the supercell being given in Table I. The supercell was built un by stacking $28(220)$ planes on the NiO side and 30 (220) planes on the Pd side. A total of 12,456 atoms were included in the simulation. The parameter $d x$ represents the width separating the two halves of the supercell. To produce simulations which include volume expansion, this width was varied by some fractional amount. It was also determined that by allowing a vacuum fraction equal to one quarter of the total supercell length normal to the interface plane, the problem of aliasing was sufficiently avoided. Instrumental parameters were as follows: $C_{s}=1.0 \mathrm{~mm}$, $\mathrm{ms}$ focal spread $=8 \mathrm{~nm}$, semi-convergence angle $=0.5 \mathrm{mR}$, and objective aperature radius $=6 \mathrm{~nm}^{-1}$. Debye-Waller factors of $0.005 \mathrm{~nm}$ for oxygen and $0.003 \mathrm{~nm}$ for both $\mathrm{Ni}$ and Pd were used. No absorption corrections were included.

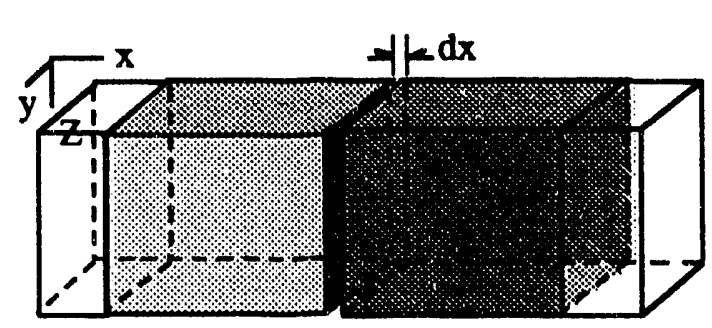

(a)

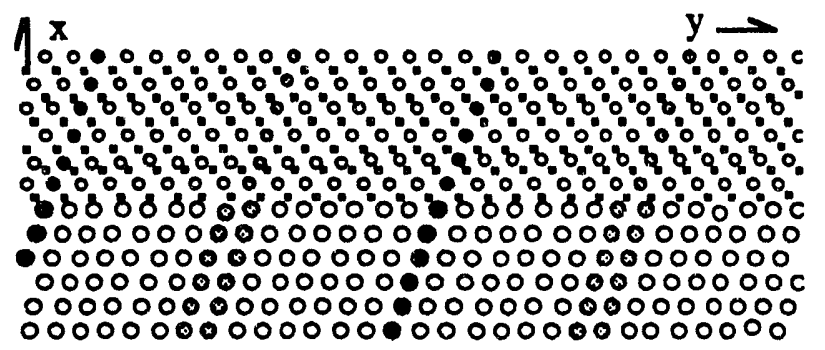

(b)

Fig.1 a) Supercell used for the multislice calculations. b) Graphic representation of the projected atom positions at the $\mathrm{Pd} / \mathrm{NiO}$ interface. Large circles $=\mathrm{Pd}$; small circles $=\mathrm{Ni}$; squares $=$ O. Shaded regions show where projected planes are in minimum (light) and maximum (dark) coincidence. $x=$ dimension perpendicular to interface; $y=$ dimension parallel to interface.

The problem of sufficient sampling was considered in detail. Shown in Table I is a comparison of the sampling parameters used in the present study to those for the previous work on $\mathrm{Ag} /$ $\mathrm{CdO}$ and $\mathrm{Cu} / \mathrm{MgO}$. In each case it was found that to faithfully reproduce the contrast effects in the boundary, sampling resolution of at least $0.1 \AA$ was necessary. To obtain quantitative information on the volume expansion, an even finer sampling resolution would be desirable. To achieve these values, the EMS routines were modified to allow a maximum array size of $2048 \times 1024$.

TABLE I

\begin{tabular}{lcc} 
System & \multicolumn{3}{c}{ Supercell Dimensions $(\AA)$} \\
\cline { 2 - 3 } & $\mathrm{x}$ & $\mathrm{y}$ \\
$\mathrm{Pd} / \mathrm{NiO}$ & 77.56 & 71.60 \\
$\mathrm{Cu} / \mathrm{NiO}$ & 71.37 & 30.07 \\
$\mathrm{Cu} / \mathrm{MgO}$ & 71.94 & 30.95 \\
$\mathrm{Cu} / \mathrm{MgO}[3]$ & 64.0 & 15.5 \\
$\mathrm{Ag} / \mathrm{CdO}[2]$ & 46.74 & 40.25
\end{tabular}

Array Size
$1024 \times 1024$
$1024 \times 1024$
$1024 \times 512$
$512 \times 128$
$512 \times 512$

\begin{tabular}{cc}
\multicolumn{3}{c}{ Real Space } & Sampling $(\AA)$ \\
\hline $\mathrm{x}$ & $\mathrm{y}$ \\
0.08 & 0.07 \\
0.07 & 0.03 \\
0.07 & 0.06 \\
$0.12 / 0.19$ & $0.12 / 0.18$ \\
0.14 & 0.12
\end{tabular}

\section{RESULTS AND DISCUSSION}

The (111) interface is made up on the oxide side of alternating $\mathrm{O}^{2-}$ and $\mathrm{Ni}^{2+}$ planes. The question of whether multislice simulations could determine the identity of the terminating plane at the interface was explored by simulating both types of structures as outlined in the previous section. For the oxygen termination, the interatomic distance between the $\mathrm{Pd}$ and $\mathrm{O}$ atoms in $\mathrm{PdO}$ $(0.201 \mathrm{~nm})$ was used to calculate $\mathrm{dx}(0.108 \mathrm{~nm})$. For the nickel termination, an average lattice 
parameter for the Pd-Ni alloy w used to calculate $\mathrm{dx}(0.214 \mathrm{~nm})$. Shown in Figure 2 are typical results from the simulations. In $e_{i}$ :? of the through-focal $(-10 \mathrm{~nm}$ to $-140 \mathrm{~nm})$ and throughthickness ( $4.1 \mathrm{~nm}, 5.9 \mathrm{~nm}, 7.4 \mathrm{~nm}$, and $8.3 \mathrm{~nm}$ ) conditions a clear distinction between the Oterminated and Ni-terminated interface could be deternined. A characteristic feature of the O-terminated structure is the periodic contrast modulation along the houndary. IIsing the NiO (112) projected plane spacings as a guide $(0.256 \mathrm{~nm})$, the periodicity is seen to be broken up into regions approximately 9 spacings and 5 spacings in length. The result is a strong periodic contrast modulation along the interface, which is consistent with the experimental observations. The Ni-terminated structure gave rise to either a very weak modulation or no modulation in contrast along the interface. Using quantitative measurement techniques as outlined in reference [8], we found that the O-terminated structure perpendicular to the interface also gave a statistically better match to the through-focal experimental images than the Ni-terminated structure. A more detailed description of this comparison is given in the next section.
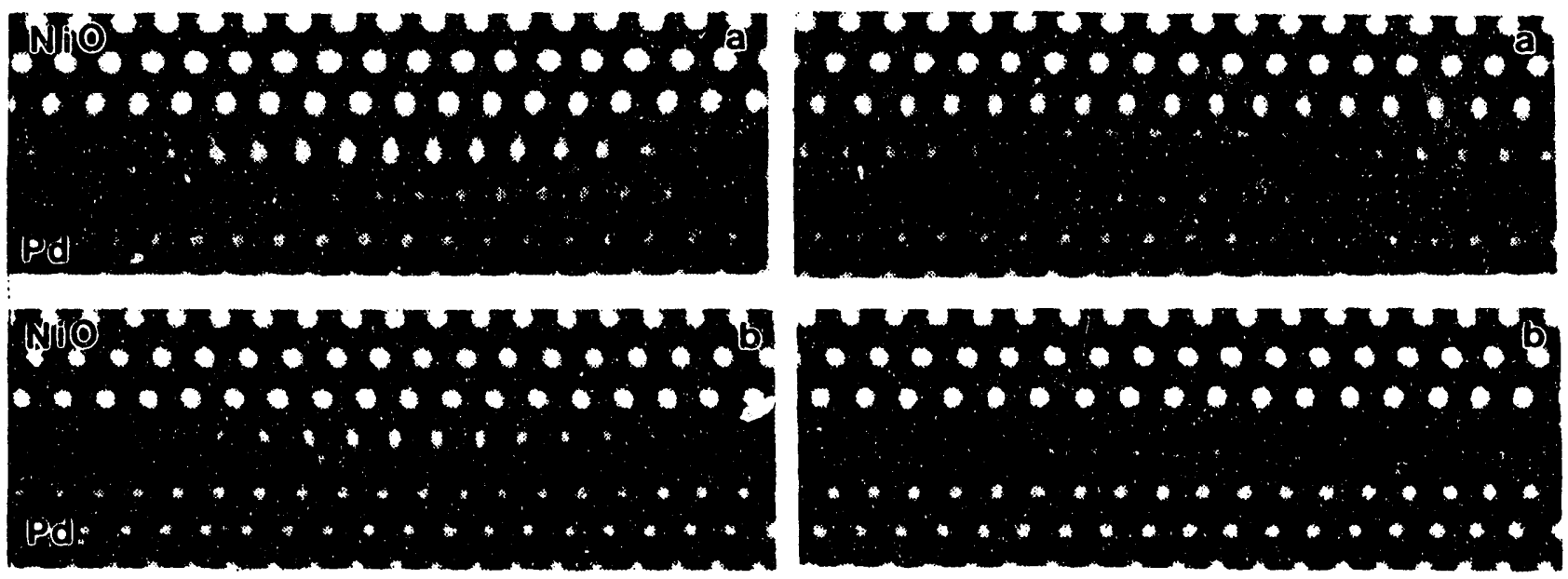

Fig. 2 Comparisons of O-terminated (left) to $\mathrm{Ni}$-terminated (right) $\mathrm{Pd} / \mathrm{NiO}[110] /(111)$ interface simulations. Thickness $=8.3 \mathrm{~nm}$. a) $-12 \mathrm{~nm}$; b) $-64 \mathrm{~nm}$. NiO is above interface. $\mathrm{Pd}$ is below.

The presence of a rigid body translation normal to the boundary (volume expansion) was explored by incorporating 5\% and $10 \%$ expansions in the $\mathrm{dx}$ value of the O-terminated structure described previously. An example comparison of the experimental observation to the $0 \%$ and $10 \%$ cases is shown in Figure 3 . The volume expansion in each case was determined by using a linear least-squares fit to the centers of gravity of a set of peak positions ('white dot') or valley positions ('black dot') on both sides of the boundary. This procedure was repeated for multiple images within the through-focal series. For the example in Fig. 3 (thickness $=8.3 \mathrm{~nm}$ ), a volume expansion of $0.001 \pm 0.007 \mathrm{~nm}$ was derived for the experimental images. It should be noted that the measurement technique could easily distinguish statistical differences between the $0 \%, 5 \%$, and $10 \%$ simulations. These results indicate that essentially zero volume expansion is associated with this interface when account is taken of the statistical errors of the measurement itself coupled with the sampling resolution of the simulations. It also illustrates the importance of sampling to better than $0.1 \AA$ for interfacial simulations.

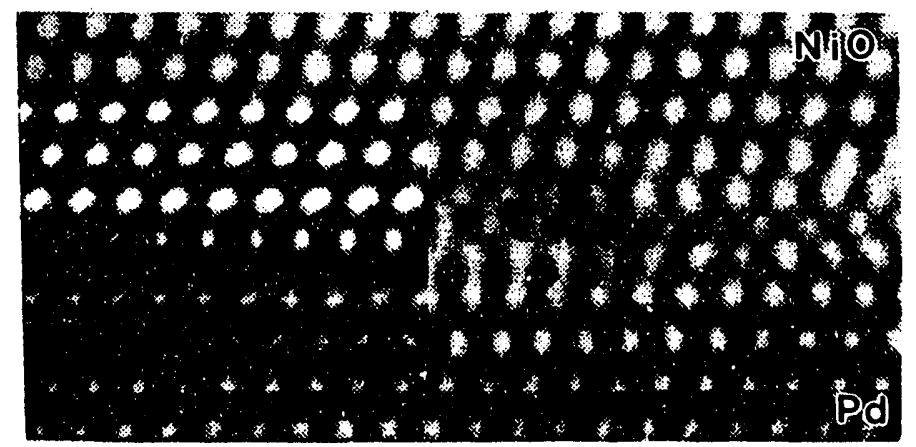

(a)

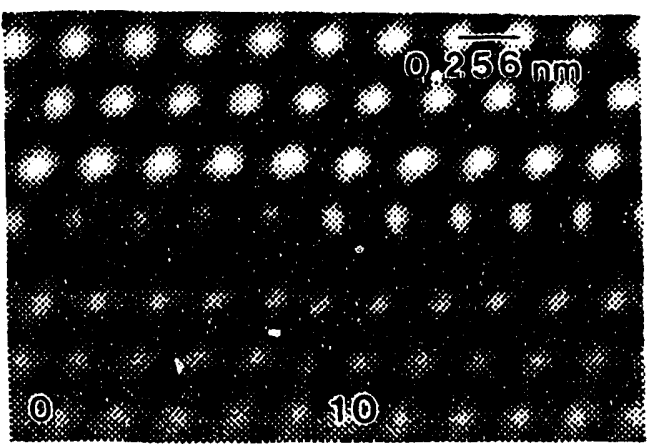

(b)

Fig. 3 (a) Experimental image with $0 \%$ volume expansion simulation inset.

(b) Comparison of the $0 \%$ simulation to the $10 \%$ simulation. 
Based simply on geometric considerations [9], pure misfit boundaries such as the (111) interface in the fcc metal/metal-oxides are predicted to form a network of misfit dislocations with Burgers vectors of the type $\underline{b}=a / 2[110]$ and line vectors along $\langle 112\rangle$ directions. This is illustrated in Fig. 4 for a hexagonal type of network. For two lattices of spacings $a_{1}$ and $a_{2}$, the network spacing $(D)$ is given by $D=|\underline{b}| / \partial \mid$, where $\partial=\left(a_{2}-a_{1}\right) /\left(a_{1}\right)$. In the $P d / N i O$ system, $D$ is approximately $4 \mathrm{~nm}$.

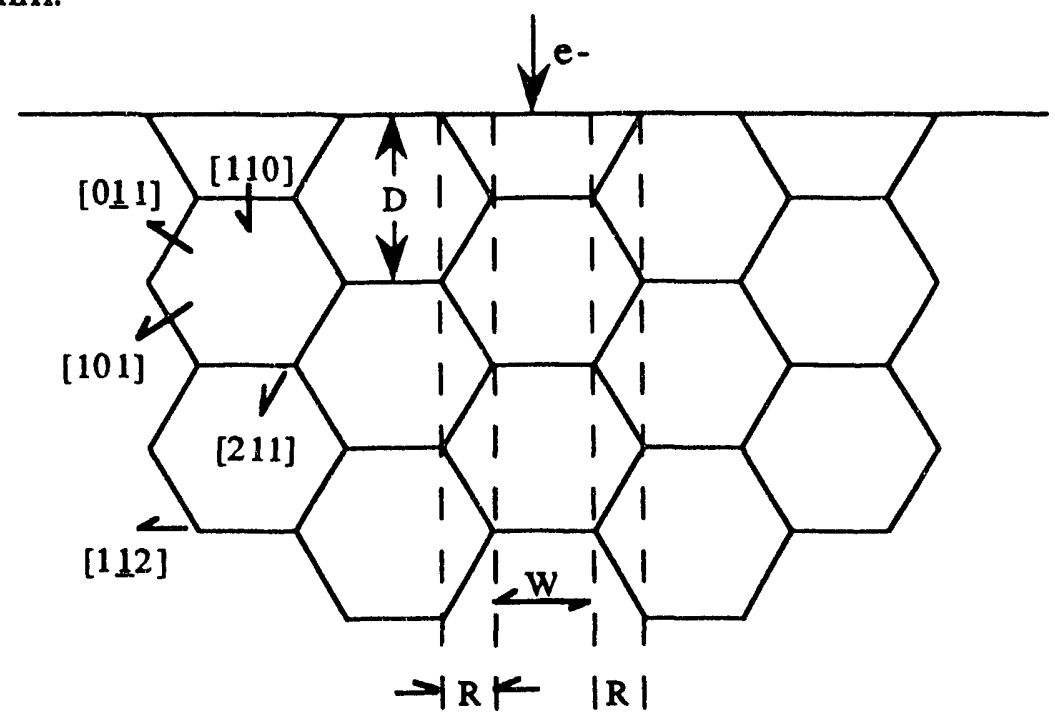

Fig. 4 Misfit dislocation model based on geometric considerations.

Although HREM and weak beam dark field microscopy are typical techniques used to study misfit dislocation problems such as this, there are inherent difficulties associated with both techniques for the imaging of the (111) interface of pure misfit fcc metal/metal-oxide systems. Even though weak beam dark field imaging will not be addressed in this paper, it should be noted that there are complications in interpretation which arise when the dislocation spacing is of the order of possible moire fringe spacings [10]. Also, the dislocation network spacings in many of these high misfit systems are below the resolution limit of the technique. The difficulties in the HREM case arise because the atomic positions in the defect structure are not projected along atomic columns parallel to the beam when viewed along [110] (the 'structure image' direction). This is clearly seen in Fig. 4. In the region marked $R$, two sets of misfit dislocations $(b=$ $a / 2[011]$ and $a / 2[101]$ ) are present which are inclined to the beam by $30^{\circ}$. Atomic columns parallel to the beam are significantly disrupted here. In the region marked $W$, however, the misfit dislocations $(b=a / 2[110])$ are parallel (or anti-parallel) to the beam. If the misfit is highly localized, atomic column resolution should be relatively unaffected in this region, but quite complex within the region $R$. On the other extreme, if the interface is completely incoherent, then the contrast along the boundary would again vary due to the relative positioning of the atoms. However, in this case the variation would be completely delocalized along the entire period, as only 2 out of 28 projected (111) planes are in alignment as they cross the interface (See Fig. 1(b)). Consequently, a strict periodicity of length $3.58 \mathrm{~nm}$ should result.

Shown in Fig. 5 is a typical HREM micrograph of the [110]/(111) Pd/NiO interface. One characteristic feature is the 9 plane $/ 5$ plane periodic contrast modulation along the boundary. A number of the experimental images we've analyzed show this feature - which agrees quite well with the simulations. Therefore, qualitatively, the rigid model image simulations alone can predict contrast modulations of this type. Similar types of contrast modulations were also reproduced in the simulations for $\mathrm{Cu} / \mathrm{NiO}$ (a 4 plane/2 plane modulation of the projected $\mathrm{NiO}(112)$ spacings along the boundary) and for $\mathrm{Cu} / \mathrm{MgO}$ (also a 4 plane/2 plane modulation of $\mathrm{MgO}$ ). This is in agreement with the experimental observations of Lu and Cosandey [3], but is in contrast to their 
simulations (where half the true period along the interface was investigated) and apparently no contrast modulations were visible until relaxations were put into the structure.
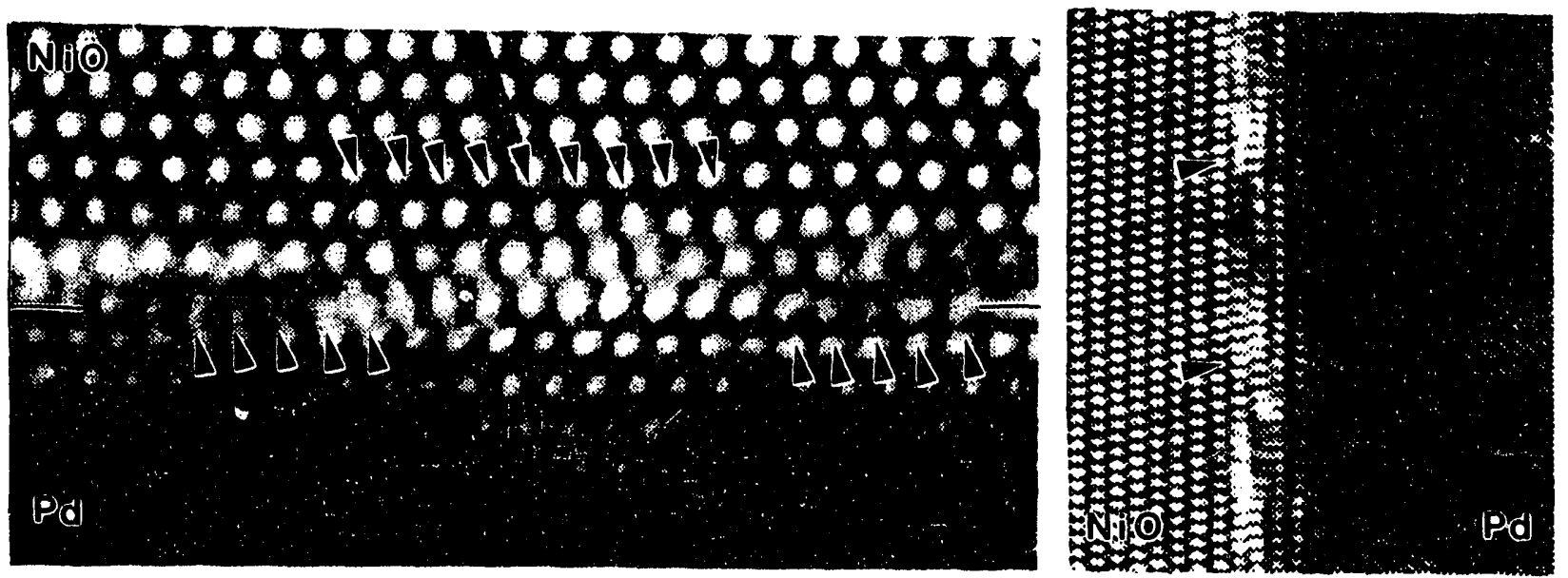

Fig. 5 (Left) Contrast modulations showing the 9/5 grouping. (Right) Same image digitally compressed. Diagonal arrows mark an entire period. Note strain $\mathrm{cc}$. trast features and bending of the lattice planes on the Pd side.

A more detailed comparison was made of the contrast modulations by evaluating an experimental versus simulated through-focal series, as shown in Fig. 6. A series of five images was analyzed, although only three are shown. Diagonal arrows on the images locate equivalent positions. The thickness of this sample was determined to be approximately $8.3 \mathrm{~nm}$. First, it can be seen that the atomic column contrast is strongly affected in the vicinity of the interface. Perhaps more evident in Fig. 5, strain contrast was typically observed on the Pd side of the interface. Closer inspections of the $9 / 5$ periodicity reveal that it was not strictly adhered to in the experimental images. The features along the interface in the experimental images were also more localized in comparison, with regions of confusion separated by regions where features were sharp and welldefined, as would be expected from the misfit dislocation model outlined in the previous section. Certain contrast features which were continuous in the simulations appeared to be broken up in the experimental images ( see, e.g., Fig. 6(c) ). These observations are all indicative of a certain degree of misfit localization, and thus we conclude that the interface cannot be incoherent. What the comparisons to rigid models fail to do, however, is to give any quantitative information on the extent of the misfit localization. This area must still be developed - most logically heginning with atomistic calculations of relaxed interfaces. The metal/metal-oxide systems await the development of appropriate atomic potentials. Calculations of relaxed interfaces between dissimilar metals (where the potentials are known) have already been applied successfully [11], revealing extremely subtle, but quantifiable effects due to misfit localization.

The authors wish to thank D. Ricker and A. Huen for their assistance. This work was funded by the U. S. Department of Energy, Basic Energy Sciences under contract W-31-109-ENG-38.

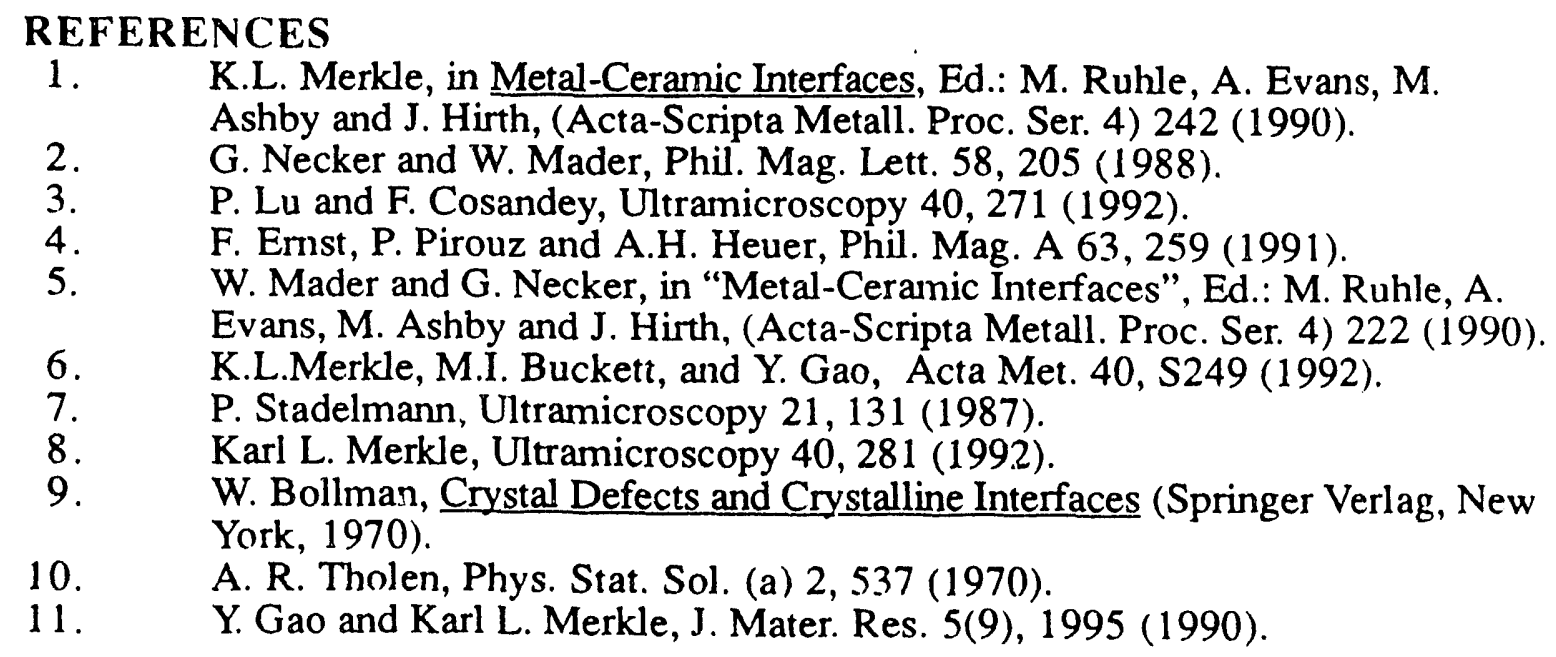


(a) defocus $=-64 \mathrm{~nm}$

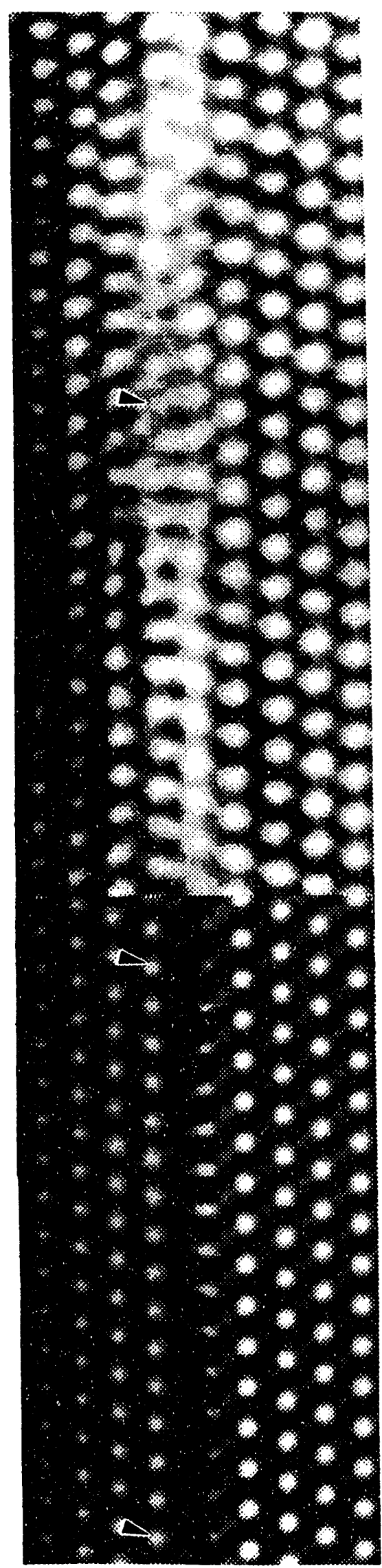

(b) defocus $=-72 \mathrm{~mm}$

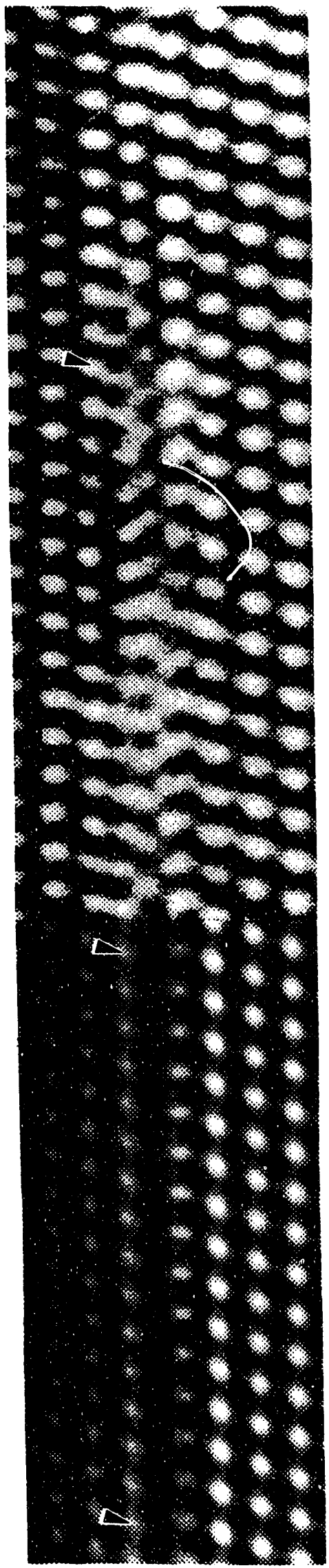

(c) lefocus $=-88 \mathrm{~nm}$

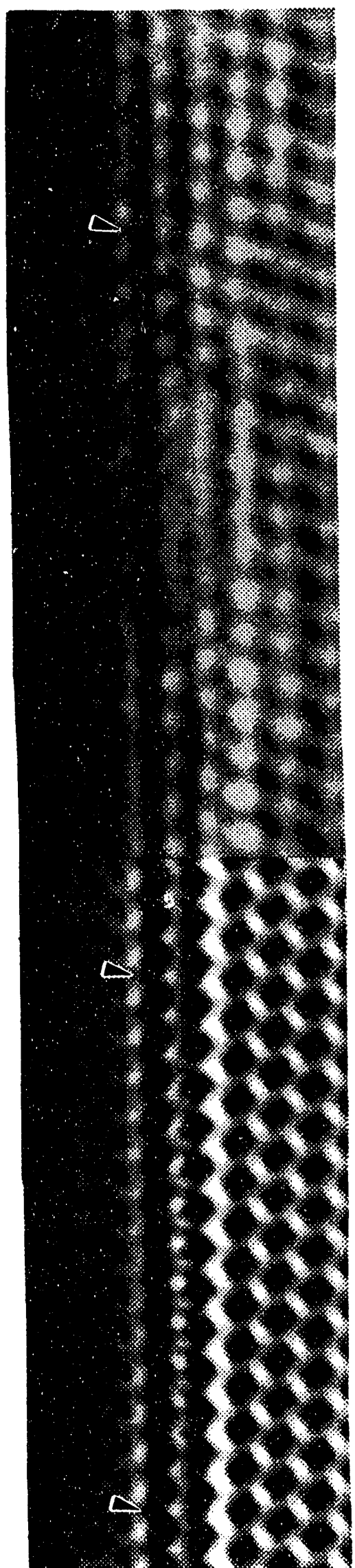

Fig. 6 Through-focal series of the $\mathrm{Pd} / \mathrm{NiO} / 110 \mathrm{~J} /(111)$ interface. Comparison is hetween

experimental images and oxygen-teminated, or volume expansion simulatioms. Thictiness is $8.3 \mathrm{~nm}$. $\mathrm{Pd}$ is to the right of the interface, $\mathrm{NiO}$ is to the left. 

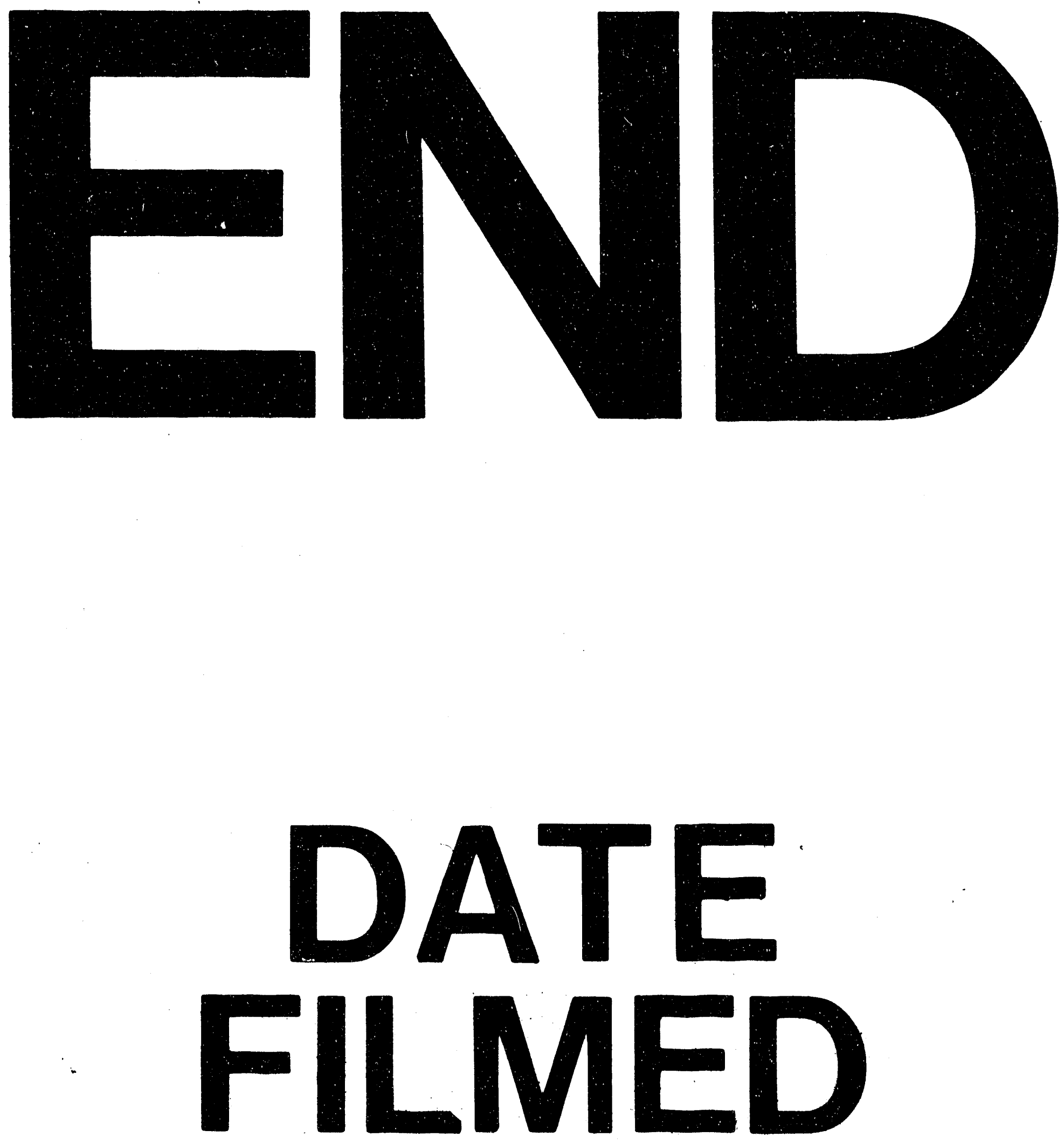

1

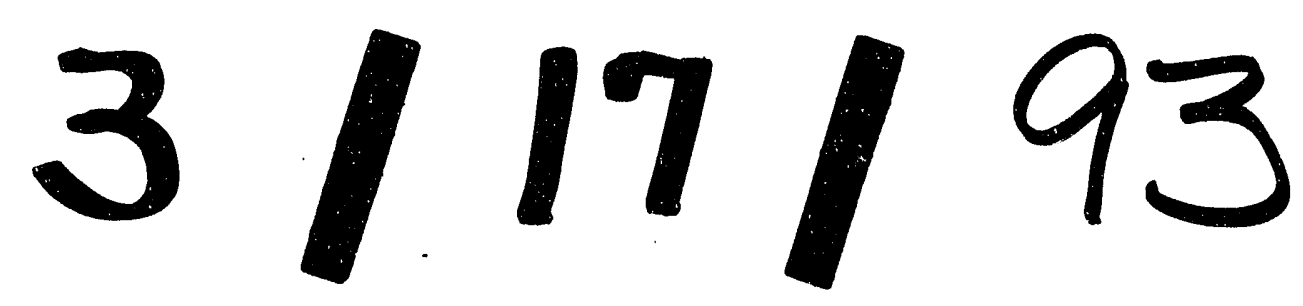


